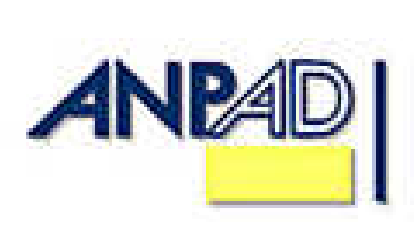

Disponível em

http://www.anpad.org.br/rac

RAC, Curitiba, v. 13, n. 3, art. 8,

p. 487-503, Jul./Ago. 2009

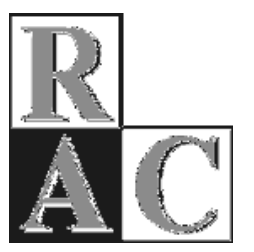

\title{
Tempo e Espaço na Contemporaneidade: uma Análise a partir de uma Revista Popular de Negócios
}

\author{
Time and Space in the Contemporaneity: an Analysis Based on a Popular Business \\ Magazine
}

\begin{abstract}
Marcia Frezza *
Mestre em Psicologia Social e Institucional pela UFRGS. Professora Auxiliar N2 no Curso de Psicologia na UNIFOR, Fortaleza/CE, Brasil.
\end{abstract}

Carmem Ligia Iochins Grisci Doutora em Psicologia pela PUC/RS. Professora Associada no PPGA/EA/UFRGS, Porto Alegre/RS, Brasil.

Cristiano Keller Kessler Mestre em Administração pela UFRGS, Porto Alegre/RS, Brasil.

* Endereço: Marcia Frezza

Av. Washington Soares, 1321, Bloco P, Sala 17, Fortaleza/CE, 60811-905. E-mail: marciafrezza@unifor.br / frezzamarcia@yahoo.com.br

Copyright (C) 2009 RAC. Todos os direitos, inclusive de tradução, são reservados. É permitido citar parte de artigos sem autorização prévia desde que seja identificada a fonte. 


\section{RESUMO}

A humanidade vive contínuas transformações no que diz respeito às formas de experimentar o tempo - cada vez mais acelerado - e o espaço - cada vez mais flexibilizado. Esse artigo é resultado de uma pesquisa exploratória de enfoque qualitativo que buscou apontar como a compressão espaciotemporal se efetiva a partir de indicadores dos modos de trabalhar e de viver contemporâneos, veiculados numa revista popular de negócios, no período de julho de 2005 a junho de 2006. Conceitos desenvolvidos por Bauman, Harvey e Virilio, em especial, mostraramse profícuos à análise do objeto de estudo. Dentre os resultados observados, destaca-se o uso intenso de tecnologias da informação, que contribui para a percepção de se estar ininterruptamente conectado, de não haver barreiras ou distâncias intransponíveis. A relação funcionário-empresa se transforma em relações pessoais e com elas se confunde. A distinção entre tempo e espaço de trabalho e tempo e espaço de família/lazer se mostra fragilizada. Os modos de trabalhar na contemporaneidade impõem padrões de autogestão para lidar com os fluxos acelerados. A era da compressão espaciotemporal mostra-se um contexto que gera diferentes impressões, sofrimentos e incertezas.

Palavras-chave: tempo; espaço; compressão; trabalho; tecnologia.

\section{ABSTRACT}

Humanity has undergone constant changes that relate to the ways people experience time - more and more accelerated - and space - more and more flexible. This article is a result of an exploratory study with a qualitative focus that seeks to comprehend how the time-space compression operates. For the analysis, indicators of the ways people work and live in the contemporaneity were used, extracted from articles published by a popular business magazine from July, 2005 to June, 2006. Concepts developed by Bauman, Harvey and Virilio were very useful for the analysis of the object of the present study. Among the results observed, we highlight the intense use of information technologies, which contribute to the development of different perceptions, such as being constantly connected and the non-existence of barriers. The distinction between time and space for work and time and space for the family/leisure is weakened. The ways of working in the contemporaneity compel people to adopt auto-management patterns to deal with the constant flux. Time-space compression seems to provoke different impressions, sufferings and (un)certainties.

Key words: time; space; compression; work; technology. 


\section{INTRODUÇÃO}

A busca pelo entendimento dos modos de trabalhar e de viver na contemporaneidade, procurando compreender os modos de subjetivação que acompanham tais processos, pode ser norteada pela problematização de duas categorias: tempo e espaço. Observa-se que essas são categorias percebidas, predominantemente, como possuidoras de essência e objetividade. Contudo um estudo cuidadoso permite a verificação de que tempo e espaço não podem ser vistos como categorias naturais dadas ou livres da interferência das relações humanas.

Bauman (1999) observou a natureza historicamente mutável do tempo e do espaço, fazendo ligação destes com o padrão e a escala de organização social. Harvey (2004) considerou que "as concepções do tempo e do espaço são criadas necessariamente através de práticas e processos materiais que servem à reprodução da vida social" (p. 189). A objetividade dessas categorias resulta de práticas materiais que podem variar geográfica e historicamente, denotando que "o tempo social e o espaço social são construídos diferencialmente" (Harvey, 2004, p. 189). Em cada momento, modo de produção e de organização humana, se dá a construção de uma maneira específica de se perceber, conceitualizar e experimentar o espaço e o tempo. Portanto podemos dizer que tempo e espaço são categorias construídas; são definições e percepções dependentes das relações humanas que se desenvolvem em determinado momento e espaço histórico. $\mathrm{O}$ direcionamento dado ao desenvolvimento e aos usos das tecnologias da informação, dos modos de produção, dos meios de transporte, das práticas de gerenciamento empresarial, das formas de se relacionar em sociedade, afeta o modo como experimentamos o tempo e o espaço, da mesma maneira com que este direcionamento é afetado pelas diferentes modalidades de experimentar essas categorias.

Nesse sentido, o presente estudo buscou apontar como a compressão espaciotemporal se efetiva, a partir de indicadores dos modos de trabalhar e de viver contemporâneos, veiculados em revista popular de negócios. Para tanto desenvolveu-se uma pesquisa exploratória, cuja análise de conteúdo e de enfoque qualitativo se deu em matérias selecionadas de 12 edições da revista Você S.A., no período de julho de 2005 a junho de 2006. A Você S.A. é revista especializada na área de negócios, que se propõe a informar as últimas novidades da gestão do trabalho e de si para um público constituído, em especial, por gestores, consultores e estudantes de administração.

Na primeira parte deste artigo encontrar-se-á uma revisão teórica sobre tempo e espaço. Na segunda parte, encontrar-se-ão os procedimentos metodológicos utilizados e, na sequiência, a apresentação e análise dos resultados. Finalmente, apresentar-se-ão as considerações finais relativas à presente compressão espaciotemporal.

\section{TEMPO E ESPAÇO NA CONTEMPORANEIDADE}

Na configuração contemporânea, segundo Virilio (1999), o progresso tecnocientífico faz surgir novo tempo com ritmo acelerado ao máximo, indicando o fim da geografia. Bauman (1999) complementou, afirmando que "as distâncias já não importam, ao passo que uma idéia de uma fronteira geográfica é cada vez mais difícil de sustentar no mundo real" (p. 19). Bauman (1999) observou, ainda, que a distância não é um dado objetivo, impessoal ou físico, mas produto social; "sua extensão varia, dependendo da velocidade com a qual pode ser vencida (e, numa economia monetária, do custo envolvido na produção dessa velocidade)" (p. 19).

De acordo com Harvey (2004), "as ordenações simbólicas do espaço e do tempo fornecem uma estrutura para a experiência, mediante a qual aprendemos quem ou o que somos na sociedade" (p. 198). Ou seja, além do tempo e do espaço serem construtos sociais, eles também definem uma estrutura que contribui para o desenvolvimento das relações sociais; portanto são categorias básicas 
para a construção de um mundo social. A partir de experiências espaciotemporais, constroem-se esquemas duradouros de percepção, de pensamento e de ação. As categorias de tempo e espaço formam um modelo comum de percepção da realidade, permitindo a construção de um mundo compartilhado, onde se desenvolvem as relações interpessoais, incluindo a linguagem, a comunicação e a ação conjunta. Ao tratar desse espaço compartilhado e construído, Bauman (2001) destacou o espaço civil - espaço onde as pessoas aprendem a agir com civilidade. A civilidade serviria como máscara que permitiria a sociabilidade, deixando distantes os sentimentos privados e as situações de poder (Sennett, 1998). Esse meio civil é o espaço onde as pessoas podem compartilhar e interagir como pessoas públicas; sendo o espaço urbano percebido como bem público, que não seria a tradução do conjunto das várias e possíveis iniciativas individuais. Dessa forma, ter civilidade ou assumir uma máscara pública "é um ato de engajamento e participação, e não um ato de descompromisso e de retirada do verdadeiro eu" (Bauman, 2001, p. 112).

Apesar de muitos lugares na cidade serem chamados de espaços públicos, Bauman (2001) observou que a maioria deles se afasta do modelo ideal de espaço civil. O autor os divide em duas categorias de direções opostas, porém complementares. A primeira categoria de espaço público não civil é aquela que impele os habitantes da cidade a serem meros passantes - são espaços com construções imponentes, não hospitaleiras, inacessíveis, estão preferencialmente vazios. Para aqueles habitantes que permanecem no local, resta-lhes a imagem de desocupados. A outra categoria de espaço público não civil tem como característica transformar os habitantes em consumidores - estimula a ação de consumir e não de interagir, uma vez que o consumo é atividade individual, de sensações experimentadas individualmente. Não é esperado que seus ocupantes conversem ou se socializem. Bauman (2001) apontou o fato de serem lugares cuidadosamente vigiados, que se tornam ilhas de ordem, salvaguardados de desocupados, mendigos e vagabundos. Segundo o autor, estes espaços físicos, ou templos de consumo, não se restringem a shopping centers, podem ser áreas de esportes, cafés, pontos turísticos, salas de concerto, teatros, entre outros.

Uma vez que não é possível compreender o tempo e o espaço independentemente da ação social (Harvey, 2004), e como é no ato que se constituem as relações de poder - estas, enquanto modos de ação que não agem diretamente sobre as pessoas, mas que agem sobre a própria ação, enquanto ação sobre ação (Foucault, 1995) - podem-se correlacionar as relações de poder e as práticas temporais e espaciais (Harvey, 2004). Da mesma forma que as categorias tempo e espaço são produtos e produtores de ações sociais, pode-se dizer que são efeitos e fontes de poder social. O poder social se articula com o controle do tempo, do espaço e do dinheiro. As formas de mensurar o tempo e de se apropriar do espaço podem converter-se em domínio sobre o dinheiro, do mesmo modo que o dinheiro pode ser usado para o domínio e a apropriação do tempo e do espaço (Harvey, 2004). Desta forma, Harvey (2004) esclareceu: "quem define as práticas materiais, as formas e os sentidos do dinheiro, do tempo ou do espaço fixa certas regras básicas do jogo social" (p. 207). Verifica-se, assim, um vínculo constitutivo entre os modos de produção de um determinado momento histórico e as formas de apreensão e construção das categorias espaço e tempo.

Para o presente artigo, interessa a problematização dessas categorias na contemporaneidade; por isso não é possível escapar de considerar as imbricações de tempo e espaço com o modo de produção capitalista. Harvey (2004) observou que a monetização das relações sociais e a perseguição de objetivos monetários modificam as qualidades do tempo e do espaço. Segundo o autor, "se o dinheiro não tem sentido independente do tempo e do espaço, sempre é possível buscar o lucro, transformando os modos de usar e definir o tempo e o espaço" (p. 209). A lógica capitalista tem a máxima de que "quanto mais rápida a recuperação do capital posto em circulação, tanto maior o lucro obtido" (Harvey, 2004, p. 209). Assim, o contínuo aumento do lucro, objetivo maior do capitalismo, está diretamente relacionado com o aumento da velocidade dos processos, velocidade conquistada não somente com o aumento dos ritmos de produção, mas também com a reconstrução do espaço, para evitar barreiras e outros empecilhos à circulação de bens e serviços. Essas transformações não atingem somente a produção, atingem principalmente as práticas de consumo, afetando de maneira direta a vida social: aceleração dupla da produção e do consumo. Essa aceleração atinge, na contemporaneidade, uma velocidade vertiginosa. 
Na medida em que o tempo se acelera e as distâncias encurtam, passado e futuro se dissolvem, ocorrendo o surgimento do reinado do presente, onde todo lugar está ao alcance de um instante, o que Harvey (2004) descreveu com o conceito de compressão espaciotemporal. O autor indicou "com essa expressão os processos que revolucionam as qualidades objetivas do espaço e do tempo, a ponto de nos forçarem a alterar, às vezes radicalmente, o modo como representamos o mundo para nós mesmos" (p. 219). A palavra compressão está relacionada à "aceleração do ritmo da vida, ao mesmo tempo que venceu as barreiras espaciais em tal grau que, por vezes, o mundo parece encolher sobre nós" (Harvey, 2004, p. 219). O que vemos nas últimas décadas é uma "intensa fase de compressão do tempo-espaço que tem tido um impacto desorientador e destrutivo sobre as práticas políticoeconômicas, sobre o equilíbrio do poder de classe, bem como sobre a vida social e cultural" (Harvey, 2004, p. 257). Ao tratar da compressão espaciotemporal, Bauman (1999) a relacionou com os processos globalizadores que estão em curso. O autor observou que os usos do tempo e do espaço são, ao mesmo tempo, diferenciados e diferenciadores, uma vez que, juntamente com as dimensões planetárias de negócios, finanças, comércio e fluxos de informações, há um processo localizador. Assim, o que para alguns é vivido como globalização, liberdade e movimento, para outros significa localização, fixação no espaço e "um destino indesejável e cruel" (Bauman, 1999, p. 8). São movimentos e mudanças que atingem, de forma diferenciada e desigual, os diversos extratos da sociedade, gerando, também, distintos efeitos nas relações sociais. Outra conseqüência da compressão espaciotemporal, apontada por Bauman (2001), é que uma vez que qualquer parte do espaço pode ser alcançada quase instantaneamente e a qualquer momento, nenhuma parte do espaço precisa ser privilegiada. Desta forma, o ponto de interrogação moveu-se do lado dos meios para o lado dos fins (Bauman, 2001, p. 137). Dá-se, assim, uma desvalorização do espaço. Contudo não se trata apenas de desinteresse. De forma mais grave, há descompromisso com o espaço e, conseqüentemente, com as relações e sujeitos sociais. A mobilidade adquirida pelos detentores do capital implica nova dissociação do poder em face das obrigações com a comunidade. A esse respeito, Bauman (1999) destacou que surgiu:

uma nova assimetria entre a natureza extraterritorial do poder e a contínua territorialidade da vida como um todo - assimetria que o poder agora desarraigado, capaz de se mudar de repente ou sem aviso, é livre para explorar e abandonar as conseqüências dessa exploração (p. 16).

Na contemporaneidade, as mudanças no mundo do trabalho têm sido cada vez mais freqüentes; são lançadas e implementadas novas formas de gestão, assim como são elaboradas novas estruturas para as empresas. Especificamente para as mudanças referentes a espaço e tempo, que ocorrem em decorrência dessas transformações e que afetam os sujeitos, é importante citar o que alguns autores caracterizam como a desterritorialização do sujeito. Segundo Pagès, Bonetti, Gaulejac e Descendre (1987), o processo de desterritorialização pode ser definido como:

o conjunto dos mecanismos que consistem em separar o indivíduo de suas origens sociais e culturais e destituí-lo de sua história pessoal para reescrevê-la no código da organização, em desenraizá-lo de sua terra originária para melhor enraizá-lo no solo empresarial, em apagar suas referências originais para substituí-las por outras mais conformes aos interesses da empresa (p. 119).

Caracteriza-se, então, como processo em que o sujeito se vê destituído do espaço que lhe era familiar; processo percebido praticamente como instantâneo - o que agrava a forma como o sujeito é afetado, podendo causar inúmeros desconfortos ou sofrimentos. É um processo que se inscreve na aceleração do tempo e flexibilização do espaço.

Virilio (1999) considerou que o caráter sucessivo cronológico dos tempos locais é suplantado pela "instantaneidade de um Tempo mundial e universal", e que "as tecnologias promovem a superexposição não apenas de toda a atividade, tornando-a interativa, mas igualmente de toda a verdade e de toda a realidade histórica" (p. 115). Segundo o autor, o Tempo-matéria, que seria o da realidade geofísica, daria lugar ao Tempo-luz, da realidade virtual, que modificaria totalmente a duração, provocando a aceleração de toda a realidade. Virilio (1999) ainda anunciou o fim da tripartição da duração - passado-presente-futuro - "o tempo que transcorre torna-se uma espécie de presente contínuo, de presente eterno" (p. 121). Isto acarretaria a perda do valor mediador da ação, em 
detrimento do imediatismo da interação. Virilio (1999) afirmou: "cada vez que desenvolvemos uma velocidade superior, reduzimos o valor de uma ação, alienando nossa capacidade de agir em proveito da de reagir, que é denominação menos otimista daquilo que atualmente chamam de interação" (p. 120). As teletecnologias contribuem para a construção do espaço das redes multimidiáticas, o que implica nova ótica, ótica global, que possibilita o aparecimento de visão panóptica, necessária para o estabelecimento do mercado visível. Esse mercado visível, mundial e único, "exige a superexposição de toda a atividade, a concorrência simultânea das empresas, das sociedades, mas também dos consumidores e, portanto, dos próprios indivíduos, e não mais unicamente de determinadas categorias de população-alvo" (Virilio, 1999, p. 62). Essa configuração de superexposição generalizada é uma evidência das muitas transformações pelas quais vem passando a modernidade na contemporaneidade. Bauman (2001) tratou dessa transição como a passagem da modernidade pesada para a modernidade leve. Uma das diferenças entre os dois momentos seria a forma de vigilância, que passa de vigilância panóptica para vigilância sinóptica (Bauman, 1999). A vigilância antes, feita por poucos, era local e impunha disciplina; servia para impedir os movimentos autônomos das pessoas, que eram confinadas e forçadas a uma dada posição. O controle no sinóptico adquire natureza global, a vigilância se dá através do ciberespaço, não importando a localidade das pessoas, o movimento é livre. A principal diferença é que a vigilância não é mais coerciva, as pessoas são seduzidas à vigilância - de vigiados elas também se tornam vigilantes (Bauman, 1999).

Da mesma forma que o controle, o capital também se torna extraterritorial, leve, e capaz de se mover com rapidez quase instantânea por toda a rede social. A esse respeito Lazzarato e Negri (2001) observaram:

a impossibilidade de determinar uma exterioridade sociológica nas relações capitalistas. Isto porque são exatamente as atividades culturais, relacionais, informacionais, cognitivas, educativas, ambientais e o tempo liberado de trabalho que se tornam os objetos e os sujeitos das novas relações de exploração e de acumulação que a revolução da informação organiza (p. 74).

Segundo Bauman (2001), a leveza e mobilidade do capital são as fontes mais importantes de incerteza, a qual se torna "a principal base da dominação e o principal fator das divisões sociais" (p. 141). Sobre o momento atual, Pelbart (2000) o vê como pós-modernidade, cujas implicações nas esferas do espaço e do tempo são inúmeras para a vida cotidiana. Aquilo que antes costumava ser definido como privado - tempo de lazer, relações familiares, âmbito da fé - perde autonomia, passando a ser amplamente penetrado "pelo que constitui o eixo do capitalismo, a relação mercadoria/consumidor e trabalhador/capitalista", que se espraia por "todos os pontos do espaçotempo social. Tudo pode ser comprado, mesmo a vida, até o tempo" (Pelbart, 2000, p. 33).

Pelbart (2000) ressaltou que o sujeito da contemporaneidade vive uma busca incessante por tempo livre e que, para isso, não pára de comprar aparelhos para poder ser dispensado das tarefas que lhe ocupam o tempo. Contudo, nessa busca, ele passa a trabalhar mais para poder adquirir os aparelhos. Assim, paradoxalmente, para obter todo o tempo o homem perde todo o tempo. O capital anteriormente "se apresentava como um doador de trabalho, agora se apresenta como um doador de tempo, quando na verdade ele faz apenas o contrário, escravizando o tempo dos trabalhadores. $\mathrm{O}$ tempo livre virou tempo escravizado, tempo investido em ganhar tempo" (Pelbart, 2000, p. 34). Especialmente, "se pensamos na informática doméstica, nessa fronteira entre trabalho, entretenimento, hipnose, fetiche, num esforço constante para otimizar o próprio desempenho" (Pelbart, 2000, p. 34). Assim, na contemporaneidade, tornou-se mais difícil distinguir o que é tempo e espaço de trabalho, tempo e espaço de produção ou tempo e espaço de lazer; e ainda, trabalho não é mais o oposto de prazer. A nova configuração do trabalho, para Lazzarato e Negri (2001), foi caracterizada como trabalho imaterial, o qual é reconhecido como a base fundamental da produção. Segundo os autores (Lazzarato \& Negri, 2001), "este processo não investe somente na produção, mas na forma inteira do ciclo reprodução-consumo: o trabalho imaterial não se reproduz (e não reproduz a sociedade) na forma de exploração, mas na forma de reprodução de subjetividade" (p. 30). Esses processos de subjetivação desenvolvem-se através dos - acelerados e constantes - fluxos de imagem, de informação, de conhecimento e de serviços que as pessoas acessam freqüentemente, por meio dos quais elas absorvem modos de ver, sentir, pensar, explicar, experimentar, trabalhar; enfim, consomem e absorvem modos 
de viver (Pelbart, 2003) - modos de viver que também são efeito das categorias tempo e espaço, assim como são reprodutores de efeitos para essas mesmas categorias.

As conseqüências das formas de conceitualizar o tempo e da compressão do tempo nas formas de trabalhar e viver contemporâneos foram investigados por vários pesquisadores (Amabile et al., 2002; Ancona, Goodman, Lawrence, \& Tushman, 2001; Perlow, 1999). Em sua pesquisa, Perlow (1999) explorou a sensação que as pessoas têm de ter muito por fazer no trabalho e a sensação de não ter tempo suficiente para fazê-lo. Segundo a autora, as constantes pressões para concluir trabalhos em cada vez menos tempo geram o que ela chama de time famine. Desta forma, haveria completa sensação de esgotamento do tempo, o que acarretaria na experimentação de dificuldades para se cumprir todas as exigências do trabalho, assim como do mundo fora dele. As constantes pressões para produzir cada vez mais rápido, num mundo que prioriza cada vez mais a criatividade, motivaram estudos que aprofundassem a compreensão da relação existente entre a compressão do tempo e a criatividade (Amabile et al., 2002). A pesquisa desenvolvida por Amabile et al. (2002) permitiu inferir que a imposição da pressão do tempo nos modos de trabalhar atuais gera estratégias cognitivas que implicam não haver tempo para pensar criativamente.

\section{AsPeCtOS METODOLÓGICOS}

O presente artigo é resultado de uma pesquisa exploratória que considerou a reflexão que Rodrigues e Morin (2004) fizeram sobre a mídia, para a escolha de uma revista popular de negócios como campo da pesquisa. Os autores observaram que a mídia exerce papel fundamental na construção do imaginário do seu público, por oferecer "possibilidades de visibilidade sem precedentes dos acontecimentos, informações e descobertas. Adicionalmente, permite um alcance e abrangência de comunicação que reconfiguram a noção de espaço público e privado" (p. 2).

Dentro do universo da mídia, Rodrigues e Morin (2004) constataram que:

a literatura de pop-management costuma ser usada como referência por gerentes, consultores, estudantes e mesmo pelos professores de administração. Por seu alcance e apelo popular, tal literatura vem desempenhando um papel importante na disseminação de novas idéias e tecnologias gerenciais, além de influenciar ... a construção das agendas dos executivos e dos pesquisadores de administração (p. 1).

A constatação de Rodrigues e Morin (2004) encontra eco na constatação de Lazzarato e Negri (2001): o fluxo de informações, imagens e conhecimento contribui para o processo de absorção de modos de ver, sentir, pensar, explicar, experimentar, trabalhar, enfim, de viver - que refletem e se refletem nos modos de experimentar o tempo e o espaço. Adicionalmente, Perlow (1999) observou que uma questão central é o modo como a gestão do tempo é conceitualizada na mídia popular. Segundo a autora, a mídia afirma que as pessoas podem fazer as mudanças necessárias em suas vidas no sentido de terem o controle da situação, desde que se esforcem para colocar em prática as táticas propostas de uso do tempo.

Tendo como base as observações dos autores, optou-se por concentrar a coleta de dados na revista Você S.A., que apresenta periodicidade mensal e é passível de ser classificada como literatura de popmanagement. Tal escolha buscou garantir um veículo de divulgação significativo da produção e reprodução de determinados modos de trabalhar e de viver na contemporaneidade.

A pesquisa privilegiou a análise de matérias - artigos, editoriais, quadros, entrevistas - publicadas em 12 edições da revista Você S.A., editadas no período de julho de 2005 a junho de 2006 . O procedimento de análise seguiu orientações de Bardin (1979). A abordagem utilizada foi baseada numa análise qualitativa da análise de conteúdo que, segundo Bardin (1979, pp. 115-116), "corresponde a um procedimento mais intuitivo, mas também mais maleável e mais adaptável, a 
índices não previstos", ou seja, "o que caracteriza a análise qualitativa é o fato de a inferência sempre que é utilizada - ser fundada na presença do índice (tema, palavra, personagem, etc.) e não sobre a freqüência da sua aparição, em cada comunicação individual". Portanto, o estudo não priorizou a freqüência com que o tema apareceu, mas privilegiou a análise qualitativa das matérias que tratam do tema objeto de estudo. Desse modo, inicialmente contemplou-se a leitura de todas as 12 edições da revista em sua totalidade. Dessa leitura, foram selecionadas para análise aquelas matérias que apresentaram relação com o objetivo proposto. As matérias selecionadas, que correspondem a um total de dezessete, serão explicitadas na apresentação e análise dos resultados. Elas foram relidas exaustivamente, tendo como suportes de leitura elementos relativos à aceleração do tempo, à flexibilização do espaço e ao encurtamento das distâncias, conforme o aporte teórico. Esse procedimento permitiu elencar categorias de cunho coletivo agrupadas em quatro indicadores de análise para o maior entendimento de como a compressão espaciotemporal se efetiva na contemporaneidade, conforme será apresentado a seguir.

\section{APRESENTAÇÃO E ANÁLISE DOS RESULTADOS}

A análise dos resultados contemplou quatro indicadores da compressão contemporânea do espaciotemporal - tecnologias da informação, espaço de trabalho, mundo da vida e mundo do trabalho, relação funcionário e empresa - que foram interpretados à luz do aporte teórico pertinente.

\section{Tecnologias da Informação}

Há forte imbricamento entre as mudanças e usos das Tecnologias da Informação [TIs] e as transformações relacionadas às categorias tempo e espaço. Deste modo, um estudo que procure aprofundar o entendimento deste imbricamento pode contribuir para maior compreensão da compressão espaciotemporal. Foram selecionadas cinco matérias com esse objetivo, que estão localizadas em três edições da revista Você S.A. Três das cinco matérias selecionadas (Incremente seu celular (Anônimo, junho/2006, p. 97); Ondas Digitais (Amanda, fevereiro/2006, p. 94); Ratinhos para todos (Anônimo, fevereiro/2006, p. 95)) procuram mostrar que as ferramentas proporcionadas a partir das inovações nas TIs podem contribuir para melhor performance e obtenção de sucesso profissional. As matérias não contêm textos longos, mas fazem forte apelo ao aspecto visual dos objetos que as ilustram. Elas expõem figuras e fotos de aparelhos de última geração, detalham suas vantagens, explicam como, por quem e para que devam ser utilizadas. As qualidades associadas às inovações são geralmente vinculadas à idéia de redução do tempo, de possibilidade de conexão constante, de facilidade de mobilidade e, principalmente, de obtenção de sucesso. Apontam, dessa forma, as ferramentas necessárias para o modo de trabalhar e de viver na contemporaneidade, de acordo com a compressão espaciotemporal.

Em outras duas dessas cinco matérias (As mazelas do mundo digital (Anônimo, fevereiro/2006, p. 15); Intoxicação high-tech (Jacomino, agosto/2005, pp. 50-51)), destaca-se o excessivo uso de aparatos tecnológicos na atualidade, o que provocaria inúmeras conseqüências para o cotidiano do profissional, especialmente no que se refere à experimentação do tempo e do espaço. Nessas matérias, é comentada a falsa promessa de que as TIs contribuiriam para a redução do tempo de trabalho e o conseqüente aumento do tempo livre - associado à idéia de que tendo mais tempo livre, as pessoas teriam a possibilidade de dispor do tempo como quisessem e teriam maior mobilidade. Contrapondo a percepção excessivamente positiva da tecnologia, essas duas matérias abordam os problemas que podem surgir a partir dessa experimentação. Para ilustrar as percepções da experimentação da compressão espaciotemporal e seu imbricamento com as TIs, foram selecionados alguns trechos contidos em matérias de duas edições da revista (As mazelas do mundo digital (Anônimo, fevereiro/2006, p. 15); Intoxicação high-tech (Jacomino, agosto/2005, pp. 50-51)). Os trechos foram agrupados em quatro categorias: utilização do tempo; espaço da transparência; controle; sentimento de estar à deriva, compondo, assim, a Tabela 1. Como é possível observar, essas categorias se mostram 
legitimadas desde uma perspectiva de continuidade que as toma em conjunto, de modo que uma determina a existência da outra.

Tabela 1: Tecnologias da Informação

\begin{tabular}{|c|c|c|c|}
\hline N. & Trechos das matérias & Autor & Edição \\
\hline \multicolumn{4}{|c|}{ Categoria: Utilização do Tempo } \\
\hline 01 & $\begin{array}{l}\text { "Por que ter mais tempo livre, mais lazer e menos trabalho não } \\
\text { passam de promessas da tecnologia." (resposta do entrevistado: } \\
\text { Naisbitt) }\end{array}$ & Jacomino & Agosto/2005, p. 50 \\
\hline 02 & $\begin{array}{l}\text { "A tecnologia do consumidor ... toma tempo." (resposta do } \\
\text { entrevistado: Naisbitt) }\end{array}$ & Jacomino & Agosto/2005, p. 50 \\
\hline 03 & $\begin{array}{l}\text { "Pior: gastamos tempo com a tecnologia, mas não gastamos mais } \\
\text { horas uns com os outros" (resposta do entrevistado: Naisbitt) }\end{array}$ & Jacomino & Agosto/2005, p. 50 \\
\hline 04 & $\begin{array}{l}\text { "A tecnologia nos ajuda a ser mais rápidos e eficientes no que já } \\
\text { estávamos fazendo. ... A internet só agiliza esse processo" (resposta } \\
\text { do entrevistado: Naisbitt) }\end{array}$ & Jacomino & Agosto/2005, p. 50 \\
\hline 05 & $\begin{array}{l}\text { "A tecnologia agiliza os processos, mas ao mesmo tempo os atrasa, } \\
\text { pois muitas vezes tira o foco do fundamento" (resposta do } \\
\text { entrevistado: Tanure) }\end{array}$ & Jacomino & Agosto/2005, p. 51 \\
\hline 06 & $\begin{array}{l}\text { "Aumentam as horas despendidas com treinamento ... tem que ficar } \\
\text { até mais tarde para dar conta do recado" (texto do autor) }\end{array}$ & Anônimo & Fevereiro /2006, p. 15 \\
\hline \multicolumn{4}{|c|}{ Categoria: Espaço da Transparência } \\
\hline 07 & $\begin{array}{l}\text { "as empresas estão cada vez mais transparentes. Todos nós podemos } \\
\text { ver o que os colegas que trabalham conosco estão fazendo." } \\
\text { (resposta do entrevistado: Naisbitt) }\end{array}$ & Jacomino & Agosto/2005, p. 51 \\
\hline 08 & $\begin{array}{l}\text { "Agora, com transparência e estrutura horizontalizada, agir de } \\
\text { maneira antiética é muito mais arriscado para o profissional do que } \\
\text { era antes". (resposta do entrevistado: Naisbitt) }\end{array}$ & Jacomino & Agosto/2005, p. 51 \\
\hline \multicolumn{4}{|c|}{ Categoria: Controle } \\
\hline 09 & $\begin{array}{l}\text { "O resultado é que, em vez de decidir por aquilo que realmente pode } \\
\text { facilitar a vida, [as pessoas] são controladas por todos esses } \\
\text { aparatos." (resposta do entrevistado: Naisbitt) }\end{array}$ & Jacomino & Agosto/2005, p. 50 \\
\hline 10 & $\begin{array}{l}\text { "se você não se tornar um escravo da tecnologia, talvez tenha mais } \\
\text { tempo para PENSAR, IMAGINAR, CRIAR". (resposta do } \\
\text { entrevistado: Naisbitt) }\end{array}$ & Jacomino & Agosto/2005, p. 50 \\
\hline \multicolumn{4}{|c|}{ Categoria: Sentimento de estar à deriva } \\
\hline 11 & $\begin{array}{l}\text { "Portanto, se [as pessoas] têm um celular, estarão entretidas, } \\
\text { divertindo-se. Se não, é o tédio. Se avaliarmos a relação ... com a } \\
\text { tecnologia, vamos concluir que ela é bastante inadequada". } \\
\text { (resposta do entrevistado: Naisbitt) }\end{array}$ & Jacomino & Agosto/2005, p. 51 \\
\hline 12 & $\begin{array}{l}\text { "não se trata da relação inadequada do homem com a tecnologia, } \\
\text { mas com a própria família. Ele [o homem] perdeu o prazer na } \\
\text { descoberta e na construção da relação". (resposta do entrevistado: } \\
\text { Tanure) }\end{array}$ & Jacomino & Agosto/2005, p. 51 \\
\hline 13 & $\begin{array}{l}\text { "Sensação de que a todo instante há uma nova demanda." (texto do } \\
\text { autor) }\end{array}$ & Anônimo & Fevereiro /2006, p. 15 \\
\hline 14 & $\begin{array}{l}\text { "Com tantas tarefas, aumenta a dificuldade para diferenciar o que é } \\
\text { urgente do que é prioritário". (texto do autor) }\end{array}$ & Anônimo & Fevereiro /2006, p. 15 \\
\hline 15 & $\begin{array}{l}\text { "Perda de habilidade com comunicação e liderança." (texto do } \\
\text { autor) }\end{array}$ & Anônimo & Fevereiro /2006, p. 15 \\
\hline 16 & $\begin{array}{l}\text { "Com o tempo as pessoas ficam desmotivadas e reclamam da falta } \\
\text { de feedback". (texto do autor) }\end{array}$ & Anônimo & Fevereiro /2006, p. 15 \\
\hline
\end{tabular}

Fonte: Revista Você S.A.

A partir dos trechos extraídos das edições da revista, foi possível identificar vários fenômenos apresentados anteriormente, à luz dos autores citados. Dentre os fenômenos, pode-se pontuar, principalmente, a compressão espaciotemporal (Harvey, Bauman e Virilio). A desvalorização do 
espaço (Bauman e Virilio) pode ser inferida nas citações inseridas na categoria sentimento de estar à deriva. Percebemos a presença da vigilância panóptica (Virilio) e/ou sinóptica (Bauman) nas citações inseridas nas categorias espaço da transparência e controle. O tempo escravizado (Pelbart) também pode ser detectado em várias citações. O espaço não-civil de consumo (Bauman) parece ser o espaço privilegiado desta imposição de aquisição de mais e melhores aparatos tecnológicos. Em geral, podemos perceber a não distinção entre tempo de trabalho e tempo de lazer (Lazzarato e Negri), uma vez que o principal objetivo do uso de ferramentas tecnológicas parece ser propiciar cada vez mais alternativas para espaços e tempos de trabalho.

No final das duas matérias que abordam vários inconvenientes que podem surgir para o trabalhador, a partir do uso excessivo das TIs, há um quadro de dicas que essencialmente informa não haver outra forma de proceder. As matérias contempladas neste item permitem, portanto, considerar a existência de uma oscilação entre ser excessivamente otimista quanto ao uso das TIs e, de certa forma, ser conformista com as conseqüências que advêm deste uso.

\section{Espaço de Trabalho}

Foram identificadas cinco matérias que abordam a relevância do espaço para a dinâmica organizacional, que produz implicações para os modos de trabalhar e, consequentemente, de viver. Três dessas matérias tratam especificamente do espaço físico da própria empresa; as outras duas contemplam a localização geográfica, onde as empresas estão instaladas.

Dentro do grupo de matérias que aborda mais especificamente o espaço físico das empresas, duas (Isto já é realidade (Schneider, fevereiro/2006, pp. 70-71); Toda mesa é sua (Nogueira, fevereiro/2006, pp. 64-69) tratam dos processos de instalação de escritórios flexíveis e arquitetura corporativa, cujas características são a diminuição do espaço ocupado pela empresa, a não existência de estações de trabalho exclusivas, o compartilhamento de mesas coletivas, a organização de estrutura móvel e flexível. Elas destacam que os objetivos das empresas convergem para o aumento da oportunidade de os funcionários socializarem/interagirem no ambiente de trabalho; a disponibilização de salas/mesas, quando os funcionários estiverem trabalhando fora da empresa; o melhoramento das condições que possam afetar a saúde (qualidade do ar, iluminação natural); e também o aumento da produtividade, a redução de custos, a redução de absenteísmo, o aumento da mobilidade, a manutenção de controle. A terceira matéria (Ative sua energia positiva (Anônimo, outubro/2005, pp. 88-89)), trata da importância da disposição dos objetos no ambiente de trabalho para a obtenção de equilíbrio, criatividade, prosperidade, poder, fama, carreira e clientes.

Quanto ao segundo grupo, que destaca a localização geográfica, onde as empresas estão instaladas, uma matéria (Entre a praia e a carreira (Costa, agosto/2005, pp. 80-81) compara os estilos de trabalhar entre duas cidades brasileiras, Rio de Janeiro e São Paulo. O texto aborda questões relacionadas ao poder, ao salário, à criatividade, à carreira, à organização e à adaptação. A idéia central da segunda matéria deste grupo (Salário: 1 executivo = 11 operários (Herzog, Dias, \& Costa, agosto/2005, p. 13)) é relacionar o grau de pobreza da região geográfica e o grau de qualificação dos profissionais dessa região com as médias da remuneração dos funcionários. A mensagem é que quanto mais pobre a região, mais baixos são os salários dos funcionários do dito chão-de-fábrica, o que ocasiona maior diferença salarial dos gerentes/diretores comparados com o salário dos funcionários do nível operacional. O texto também faz uma relação entre a pobreza da região e a desqualificação da mão-deobra local. Pode-se imaginar que, uma vez que a reportagem destaca que nas regiões mais pobres a mão-de-obra não é qualificada, os gerentes e diretores contratados são de outras regiões, das consideradas mais desenvolvidas. Isto remete ao processo localizador descrito por Bauman (1999), as melhores posições e salários são privilégio dos globais, à comunidade local resta a esperança de um emprego qualquer, de baixo salário. Para ilustrar a análise e as considerações desenvolvidas, foram selecionados trechos das matérias aqui destacadas, que estão listados na Tabela 2: 
Tabela 2: Espaço de Trabalho

\begin{tabular}{|c|c|c|c|}
\hline N. & $\begin{array}{l}\text { Trechos das matérias } \\
\end{array}$ & Autor & Edição \\
\hline 17 & $\begin{array}{l}\text { "Daí, a proliferação de salas de reunião, que também podem ser } \\
\text { usadas no dia-a-dia, e das áreas de convivência, para que as pessoas } \\
\text { socializem e, dependendo do caso, até as utilizem de vez em quando } \\
\text { para trabalhar". (texto do autor) }\end{array}$ & Nogueira & Fevereiro /2006, p. 64 \\
\hline 18 & $\begin{array}{l}\text { "o departamento que antes ocupava uma área de } 400 \mathrm{~m}^{2}, \text { encolheu } \\
\text { para } 200 \mathrm{~m}^{2} \text {. (texto do autor) }\end{array}$ & Nogueira & Fevereiro /2006, p. 64 \\
\hline 19 & $\begin{array}{l}\text { "Os funcionários se queixavam de ter de tirar seus objetos das } \\
\text { mesas e tinham medo de ficar mais vulneráveis em um ambiente tão } \\
\text { impessoal". (resposta do entrevistado: Rocha) }\end{array}$ & Nogueira & Fevereiro /2006, p. 65 \\
\hline 20 & $\begin{array}{l}\text { "A saída foi fazer simulação e treinamentos para mostrar a eles a } \\
\text { necessidade de mudar. Foi um treino de desapego". (texto do autor) }\end{array}$ & Nogueira & Fevereiro /2006, p. 65 \\
\hline 21 & $\begin{array}{l}\text { "Não tinha sentido manter estações de trabalho exclusivas para } \\
\text { quem fica visitando uma vez por semana". (resposta do } \\
\text { entrevistado: Rocha) }\end{array}$ & Nogueira & Fevereiro /2006, p. 65 \\
\hline 22 & $\begin{array}{l}\text { "Essa história de não ter um lugar fixo é ótimo para você treinar a } \\
\text { sua capacidade de adaptação". (resposta do entrevistado: Souza) }\end{array}$ & Nogueira & $\begin{array}{l}\text { Fevereiro /2006, pp. 66 } \\
67\end{array}$ \\
\hline 23 & $\begin{array}{l}\text { "Com a mudança, a empresa conseguiu otimizar o espaço e reduzir } \\
\text { o seu custo operacional". }\end{array}$ & Nogueira & Fevereiro /2006, p. 68 \\
\hline 24 & $\begin{array}{l}\text { "Todos os dias as mesas são fiscalizadas e quem deixa suas coisas lá } \\
\text { as encontra no dia seguinte em um carrinho que fica no meio do } \\
\text { corredor." (texto do autor) }\end{array}$ & Nogueira & $\begin{array}{l}\text { Fevereiro /2006, pp. 68 } \\
69\end{array}$ \\
\hline 25 & $\begin{array}{l}\text { "investir em espaços próprios para dar um tempo do batente é uma } \\
\text { ótima opção para garantir a satisfação e, indiretamente, a } \\
\text { produtividade do time”. (texto do autor) }\end{array}$ & Schneider & Fevereiro /2006, p. 70 \\
\hline 26 & $\begin{array}{l}\text { "Hoje, equipamentos cada vez mais compactos permitem mesas } \\
\text { idem - e as empresas comemoram, porque economizar espaço (leia- } \\
\text { se dinheiro) é uma questão importante para elas". (texto do autor) }\end{array}$ & Schneider & Fevereiro /2006, p. 71 \\
\hline 27 & $\begin{array}{l}\text { "Quando preciso fazer ligações ou tratar de assuntos confidenciais } \\
\text { uso as salas de reunião". (resposta do entrevistado: Haidar) }\end{array}$ & Schneider & Fevereiro /2006, p. 71 \\
\hline 28 & $\begin{array}{l}\text { "olhar para fora relaxa e faz a pessoa voltar para o trabalho com } \\
\text { carga redobrada". (texto do autor) }\end{array}$ & Schneider & Fevereiro /2006, p. 71 \\
\hline 29 & $\begin{array}{l}\text { "É uma tendência proporcionar às pessoas a maior possibilidade de } \\
\text { controle possível sobre o ambiente de trabalho". (resposta do } \\
\text { entrevistado: Orstein) }\end{array}$ & Schneider & Fevereiro /2006, p. 71 \\
\hline 30 & $\begin{array}{l}\text { "Queria ficar próximo do círculo de decisão para dar mais } \\
\text { visibilidade ao meu trabalho". (resposta do entrevistado: Felizzola) }\end{array}$ & Costa & Agosto/2005, p. 80 \\
\hline 31 & $\begin{array}{l}\text { "Impossível negar que em São Paulo o dinheiro tem poder". (texto } \\
\text { do autor) }\end{array}$ & Costa & Agosto/2005, p. 80 \\
\hline 32 & $\begin{array}{l}\text { "Logo o carioca percebe que fazer relacionamentos na capital } \\
\text { paulista significa ampliar os negócios e a perspectiva profissional". } \\
\text { (texto do autor) }\end{array}$ & Costa & Agosto/2005, p. 80 \\
\hline 33 & $\begin{array}{l}\text { "Os paulistanos são mais organizados, focados e trabalham por } \\
\text { resultado ... Os cariocas são criativos e têm grande capacidade de } \\
\text { adaptação". (Carvalhal como citado por Costa) }\end{array}$ & Costa & Agosto/2005, p. 80 \\
\hline
\end{tabular}

Fonte: Revista Você S.A.

A análise das matérias permitiu verificar, mais uma vez, a indicação da presença de fenômenos abordados pelos autores contemplados na discussão teórica do presente artigo. Dentre os fenômenos destacam-se os processos de desterritorialização e de reterritorialização, especialmente quando é apontada a necessidade de o trabalhador se desvencilhar daquilo que lhe é familiar e se adaptar às novas estruturas. Esses processos são claramente perceptíveis nas citações 20, 21, 22, 24, 30 e 31 (Tabela 2). De modo geral, o exame das citações listadas na Tabela 2 permite apontar a tendência cada vez mais intensa de valorizar a potência criativa do trabalhador - o trabalho imaterial (Lazzarato \& Negri, 2001), fenômeno que parece ser indissociável da compressão espaciotemporal. Identificam-se, ainda, indícios do espaço não-civil dos passantes (Bauman, 2001), uma vez que a organização 
espacial, ao contrário do que é pregado, não parece visar uma conformação que satisfaça o trabalhador, a ponto de deixá-lo plenamente relaxado. O direcionamento predominante parece salientar que os trabalhadores têm de ter a exata noção de que estão ali apenas de passagem, que não devem sentir-se tão à vontade. Assim, a nova organização espacial deve apenas tornar o ambiente economicamente e suficientemente estimulante para o aumento da produtividade. Essas tendências e movimentos podem ser ilustrados com mais ênfase nas citações 19, 21 e 24 (Tabela 2).

A não distinção entre espaço de trabalho e espaço da vida privada também é perceptível nos trecho destacados das matérias selecionadas para as reflexões feitas neste item, em especial nas citações 17 e 27 (Tabela 2). Contudo a análise deste fenômeno será amplamente desenvolvida, a seguir, na discussão do terceiro indicador da compressão espaciotemporal.

\section{Mundo da Vida e Mundo do Trabalho}

Um tema bastante recorrente nas matérias analisadas refere-se à fronteira entre as relações familiares e atividades de lazer - conjunto que aqui é identificado como mundo da vida - e as relações e atividades de trabalho - caracterizado como mundo do trabalho. Observa-se grande indiferenciação entre esses dois mundos, que antes eram claramente percebidos como distintos. A flexibilização dos espaços de trabalho e a instantaneidade da comunicação parecem implicar intensa invasão do mundo do trabalho no mundo da vida. O tempo de trabalho não está mais contido em determinado período do dia ou espaço específico; ele se expande para horários de convívio familiar, para locais distantes do escritório. A partir da análise de cinco matérias (Mães executivas (Dias, setembro/2005, pp. 62-65); Há vida lá fora (Mari, novembro/2005, pp. 36-39); Pais sem happy-hour, filhos sem recreio (Oliveira, novembro/2005, pp. 70-74); Fora de controle (Mari, agosto/2005, pp. 58-59); Quer trabalhar meio período? (Schibuola, novembro/2005, pp. 40-41)), pode-se pontuar indícios dessa tendência, que parece ser forte característica da contemporaneidade. Assim como nos itens anteriores, foram destacados trechos das matérias selecionadas, dispostos na Tabela 3, com o intuito de enriquecer as análises aqui desenvolvidas.

Tabela 3: Mundo da Vida e Mundo do Trabalho

\begin{tabular}{|c|l|c|c|}
\hline N. & \multicolumn{1}{|c|}{ Trechos das matérias } & Autor & Edição \\
\hline 34 & $\begin{array}{l}\text { "Se dão um celular para você e ele fica ligado o tempo todo, } \\
\text { em função do tempo globalizado, isso é um tipo de escravidão } \\
\text { moderna. Em vez de abrirem espaços de liberdade, as novas } \\
\text { tecnologias estão sendo usadas para acelerar o trabalho". } \\
\text { (resposta do entrevistado: Oliveira) }\end{array}$ & Mari & Novembro/2005, p. 38 \\
\hline 35 & $\begin{array}{l}\text { "a vida como está organizada hoje não cabe em 24 horas. As } \\
\text { demandas do universo privado foram absolutamente } \\
\text { desvalorizadas". (resposta do entrevistado: Oliveira) }\end{array}$ & Mari & Novembro/2005, p. 36 \\
\hline 36 & $\begin{array}{l}\text { "o vencedor, na maioria das vezes, é alguém sem vínculos, sem } \\
\text { responsabilidades afetivas. Porque a maioria dos profissionais } \\
\text { vai sofrer muito na tentativa de conciliação da carreira com a } \\
\text { vida privada". (resposta do entrevistado: Oliveira) }\end{array}$ & Mari & Novembro/2005, p. 38 \\
\hline 37 & $\begin{array}{l}\text { "Há seis meses, a executiva se separou do namorado e desde } \\
\text { então toca a vida com as duas filhas sozinha. Acorda as 6h30 e } \\
\text { dificilmente vai para a cama antes da meia-noite". (texto do } \\
\text { autor) }\end{array}$ & $\begin{array}{l}\text { Dias } \\
\text { "Sheila definiu que o horário oficial do despertador é 5h45. Só } \\
\text { assim ela consegue tomar café calmamente ao lado do filho e } \\
\text { ainda levá-lo ao colégio (a aula começa as 7h20), antes de } \\
\text { iniciar o expediente. Como ela não almoça em casa e só sai do } \\
\text { trabalho depois das 8 da noite, nunca encontra o filho acordado, } \\
\text { já que a orientação é para que ele vá dormir às 19h30". (texto } \\
\text { do autor) }\end{array}$ & Setembro/2005, p. 65 \\
\hline 38 & Oliveira & Novembro/2005, p. 71 \\
\hline
\end{tabular}




\section{(conclusão)}

\section{Tabela 3: Mundo da Vida e Mundo do Trabalho}

\begin{tabular}{|c|l|c|c|}
\hline N. & \multicolumn{1}{|c|}{ Trechos das matérias } & Autor & Edição \\
\hline 39 & $\begin{array}{l}\text { "não é sobre trabalhar menos. É sobre reequilibrar o trabalho } \\
\text { para os momentos em que você está mais produtivo ... Eu digo: } \\
\text { fique em casa, tome café com seus filhos e venha às 10:30, } \\
\text { quando não tem trânsito. Estou ajudando a administrar o } \\
\text { stress". (resposta do entrevistado: Semler) }\end{array}$ & Mari & Agosto/2005, p. 58 \\
\hline 40 & $\begin{array}{l}\text { "A gente diz para as pessoas trabalharem onde quiserem; mas, } \\
\text { para cumprir suas metas, algumas delas precisam trabalhar 16 } \\
\text { horas por dia. Não dá para abolir a competição do mercado". } \\
\text { (resposta do entrevistado: Semler) }\end{array}$ & Mari & Agosto/2005, p. 59 \\
\hline 41 & $\begin{array}{l}\text { "a jornada de meio período é a última novidade do programa de } \\
\text { flexibilidade da GE do Brasil, que existe há mais de três anos. } \\
\text { O funcionário tem mais duas opções: definir seu próprio } \\
\text { horário de entrada e saída ou trabalhar em casa". (texto do } \\
\text { autor) }\end{array}$ & $\begin{array}{l}\text { Schibuola } \\
\text { "Os que adotam o home office ... contam com um escritório em } \\
\text { casa, montado pela GE, e podem dividir com a empresa os } \\
\text { gastos com energia". (texto do autor) }\end{array}$ & Novembro/2005, p. 41 \\
\hline Fonte: Revista Você S.A A & Novembro/2005, p. 41 \\
\hline
\end{tabular}

Fonte: Revista Você S.A.

Acompanhando o movimento de fragilização da fronteira entre os dois mundos, percebe-se a desvalorização do mundo da vida, conforme aponta a citação 35 (Tabela 3). Outros efeitos podem ser destacados, como terceirização da criação dos filhos, crises de relacionamento e sofrimentos diversos perceptíveis nas citações 36, 37 e 38 (Tabela 3). Apesar de as entrevistas e opiniões destacadas de matérias da revista abordarem o sofrimento trazido por essa extensão do mundo do trabalho no mundo da vida, a percepção que prevalece é a de que essa situação é natural, não podendo ser modificada e que, para sobreviver nesse contexto, todos deveriam adaptar-se às mudanças, o que pode ser identificado em várias citações da Tabela 3.

As tensões entre os dois mundos, decorrentes da compressão espaciotemporal, também são verificadas na matéria 'Mães executivas' (Dias, setembro/2005), cuja idéia central é mostrar que algumas empresas estão tendo uma atitude positiva com relação às mulheres/funcionárias que engravidam, uma vez que a empresa não deixa de promovê-las pelo fato de engravidarem. Porém, após o período de licença maternidade, a funcionária retorna ao padrão de atividades anteriores, o que dificulta o convívio familiar - situação identificada na experiência de uma executiva (citação 37, Tabela 3). O fenômeno da terceirização dos filhos é destacado na matéria 'Pais sem happy-hour, filhos sem recreio' (Oliveira, novembro/2005), que mostra como executivos e profissionais de sucesso encaminham a formação dos filhos. Verifica-se o pouco contato familiar e o excesso de cursos e atividades dos filhos, cujas rotinas se parecem muito com as dos pais. De certo modo, a terceirização ultrapassou os limites do mundo do trabalho para começar a ser utilizada nas relações afetivas e no lazer. Nessa matéria há, ainda, um quadro de dicas dadas por dois especialistas da área educacional, que tangenciam algumas críticas à intensa rotina imposta às crianças. Contudo a noção privilegiada é a de que esse direcionamento é correto, pois o volume de atividades vai, no futuro, proporcionar uma série de vantagens para as crianças. As dicas transmitem a idéia de que os pais devem equilibrar suas atividades profissionais com a interação com os filhos, reservando algum tempo em que a família esteja reunida, basicamente durante as refeições, o que pode ser verificado na citação 38 (Tabela 3).

As matérias não questionam a organização do trabalho, o excesso de trabalho e a falta do convívio familiar, muito menos a expansão do tempo de trabalho em outros domínios da vida. A solução para equilibrar trabalho e família estaria na flexibilização da jornada de trabalho, conforme apontam as citações 39 e 40 (Tabela 3). A percepção dominante sugere ainda que a flexibilização das horas de trabalho proporcionaria trocar algumas horas de trabalho por tempo de lazer. Por outro lado, a análise do que é visibilizado nos trechos das matérias (Tabela 3) possibilita a percepção de que, ao contrário 
de privilegiar o bem-estar do funcionário, as mudanças são importantes para que este trabalhe mais, com maior produtividade; o que importa são os resultados, o alcance das metas, não interessando onde, quando ou quanto o funcionário terá de trabalhar. A matéria 'Quer trabalhar meio período?' (Schibuola, novembro/2005) ressalta que as mudanças que acompanham a compressão do espaçotempo aliariam as necessidades da empresa com as dos funcionários, o que proporcionaria vantagens igualmente mútuas. Porém o conteúdo da citação 34 (Tabela 3) destaca o desequilíbrio e tensão dessas relações.

\section{Relação Funcionário-Empresa}

Foram selecionadas duas matérias que abordam o relacionamento entre o funcionário e a empresa, que evidenciam imbricações significativas com o tempo e o espaço. A primeira (Felizes para sempre (Bottoni, abril/2006, pp. 48-50)) delas tem como objetivo principal analisar a relação entre o funcionário e a empresa, fazendo desta relação uma analogia com os estágios do casamento. O texto destaca a necessidade de se estabelecer transparência, conversas e novas metas, de acordo com os anos de empresa que o funcionário tenha. Aqui, mais uma vez, pode observar-se a crescente indistinção entre assuntos referentes ao trabalho e assuntos referentes à vida privada, uma vez que se utilizam conceitos relacionados com o casamento para explicar fenômenos relacionados com o trabalho.

A segunda matéria 'Quando dizer não ao chefe' (Rego, agosto/2005, pp. 89-91) avalia treze situações em que as empresas podem passar dos limites com relação às exigências feitas aos seus funcionários. Para cada contexto, é dada uma dica de como o funcionário deve reagir e é feito um comentário sobre a reação indicada. A título de ilustração, construiu-se um quadro (Tabela 4) com onze dos treze contextos apresentados pela matéria. Esses onze foram destacados por abordarem fenômenos referentes ao tempo e ao espaço.

Tabela 4: Relação Funcionário-empresa

\begin{tabular}{|c|c|c|c|}
\hline N. & Contexto & Dica & Comentário da Revista \\
\hline i & $\begin{array}{l}\text { Trabalhar no fim de } \\
\text { semana. }\end{array}$ & Diga sim & $\begin{array}{l}\text { "Mas evite exageros. ... quando há necessidade. Nesse caso, } \\
\text { aceite o trabalho, e solicite uma folga depois". (p. 89) }\end{array}$ \\
\hline ii & $\begin{array}{l}\text { Manter o celular sempre } \\
\text { ligado. }\end{array}$ & Diga sim & $\begin{array}{l}\text { "É evidente que se perde um pouco do sossego, mas pega bem } \\
\text { oferecer à empresa a colaboração de que ela necessita". (p. 89) }\end{array}$ \\
\hline iii & $\begin{array}{l}\text { Viagens a trabalho e } \\
\text { proposta para mudar de } \\
\text { cidade. }\end{array}$ & Negocie & $\begin{array}{l}\text { "Uma vez ou outra dá para recusar uma viagem de trabalho, mas } \\
\text { só se houver um forte motivo. ... Mas saiba que pode perder } \\
\text { futuras promoções". (p. } 89 \text { ) }\end{array}$ \\
\hline iv & $\begin{array}{l}\text { Atividades que fogem às } \\
\text { suas funções usuais. }\end{array}$ & Diga sim & $\begin{array}{l}\text { "As empresas estão enxutas e o profissional precisa ser flexível } \\
\text {... Mas lembre-se de que atividades extras podem representar } \\
\text { uma oportunidade de crescer e expandir seus conhecimentos". (p. } \\
90 \text { ) }\end{array}$ \\
\hline $\mathrm{V}$ & $\begin{array}{l}\text { Passar do horário } \\
\text { regularmente. }\end{array}$ & $\begin{array}{l}\text { Fique } \\
\text { atento }\end{array}$ & $\begin{array}{l}\text { "demonstra falta de organização do profissional ou da empresa". } \\
\text { (p. 90) }\end{array}$ \\
\hline vi & $\begin{array}{l}\text { Não ganhar folga nem } \\
\text { remuneração pelas horas } \\
\text { extras. }\end{array}$ & Negocie & $\begin{array}{l}\text { "A vantagem é que tem muito mais abertura para solicitar folgas } \\
\text { e flexibilidade no horário, sempre que precisar se ausentar". (p. } \\
90 \text { ) }\end{array}$ \\
\hline vii & $\begin{array}{l}\text { Usar seu carro, seu } \\
\text { computador e seu celular } \\
\text { para trabalhar. }\end{array}$ & $\begin{array}{l}\text { Peça } \\
\text { reembolso }\end{array}$ & $\begin{array}{l}\text { "Mas há exceções. ... Se o notebook da companhia quebrar, } \\
\text { ofereça o seu. A empresa vai enxergar seu profissionalismo". (p. } \\
90)\end{array}$ \\
\hline viii & $\begin{array}{l}\text { Almoços, happy hours e } \\
\text { eventos em geral, ligados } \\
\text { ao trabalho. }\end{array}$ & Diga sim & $\begin{array}{l}\text { "Mas evite exageros. Se é algo que trará um retorno efetivo para } \\
\text { a empresa, não dá para negar. ... A carreira corre riscos, quando } \\
\text { você sempre diz não a eventos que fazem parte da sua função." } \\
\text { (p. 91) }\end{array}$ \\
\hline ix & $\begin{array}{l}\text { Cancelar as férias na } \\
\text { última hora por causa da } \\
\text { empresa. }\end{array}$ & Negocie & $\begin{array}{l}\text { "Às vezes o profissional precisa mesmo desistir das férias ou } \\
\text { reduzir a duração delas". (p. 91) }\end{array}$ \\
\hline
\end{tabular}


(conclusão)

Tabela 4: Relação Funcionário-empresa

\begin{tabular}{|l|l|l|l|}
\hline N. & \multicolumn{1}{|c|}{ Contexto } & \multicolumn{1}{c|}{ Dica } & \multicolumn{1}{c|}{ Comentário da Revista } \\
\hline x & $\begin{array}{l}\text { Participar de cursos que você não } \\
\text { gostaria de fazer. }\end{array}$ & $\begin{array}{l}\text { Mostre } \\
\text { opções }\end{array}$ & $\begin{array}{l}\text { "O treinamento em questão pode fazer parte da estratégia } \\
\text { da empresa para prepará-lo para uma nova função". (p. 91) }\end{array}$ \\
\hline xi & $\begin{array}{l}\text { Aceitar novas responsabilidades } \\
\text { sem aumento de salário. }\end{array}$ & Diga sim & $\begin{array}{l}\text { "Se é para o seu crescimento, incorpore novas } \\
\text { responsabilidades, mesmo sem uma compensação } \\
\text { financeira". (p. 91) }\end{array}$ \\
\hline
\end{tabular}

Fonte: Rego (Agosto/2005, pp. 89-91).

O objetivo aparente da matéria é proporcionar ao leitor uma base para reflexão sobre possíveis contextos em que um funcionário pode negar uma solicitação da empresa e como deveria reagir em cada situação. Uma leitura breve nos conduziria ao erro de concluir que a principal preocupação seria com o excesso de exigências que as empresas fazem aos seus funcionários. Contudo, na análise das conduções privilegiadas pela matéria, percebe-se a tendência em induzir o leitor a pensar que o funcionário sempre tem a ganhar com as exigências feitas pelas empresas: promoção, reconhecimento, crescimento, expansão. E, desta forma, não teria melhor alternativa do que ceder às solicitações da empresa.

Os fenômenos visibilizados pelas matérias da revista foram divididos entre os quatro indicadores tecnologias da informação, espaço de trabalho, mundo da vida e mundo do trabalho, relação funcionário e empresa - com o propósito de sistematizar a análise desenvolvida. Uma vez que as discussões suscitadas em cada um deles evidenciaram o forte imbricamento dos fenômenos e dos indicadores de análise entre si, pode-se dizer que cada um dos quatro legitima o conjunto.

\section{CONSIDERAÇÕES FINAIS}

Os resultados da pesquisa permitem inferir que o tempo e o espaço são percebidos e experimentados de forma diferenciada. Demonstram como e quanto as percepções do tempo e do espaço não traduzem com fidelidade o simples cálculo das horas ou dos quilômetros: o tempo está cada vez mais curto e passa cada vez mais rápido; as distâncias e as fronteiras devem ser transponíveis quase instantaneamente.

Foi possível apontar que o maior acesso às TIs proporciona comunicação imediata e ampla acessibilidade, além de disponibilizar ferramentas sofisticadas que servem para a produção do trabalho imaterial, móvel e circulante. Este contexto, pelo que foi verificado, intensifica a lista de requisições impostas ao trabalhador. Dessa forma, as relações entre empresa e funcionário se transformam, na medida em que os espaços e os tempos de trabalho se flexibilizam. $\mathrm{O}$ espaço físico das empresas assume novas características: para funcionários itinerantes estabelecem-se locais itinerantes, com mesas compartilhadas e ambientes impessoais. Os espaços sem divisórias, e usados por muitos, evidenciam as novas formas de controle. Os tempos e os espaços de trabalho flexibilizados propiciam o prolongamento das horas trabalhadas, seja onde se estiver. Os resultados mostraram quanto a nova ordem do mundo do trabalho afeta os direcionamentos do mundo da vida. Dá-se um processo de indiferenciação entre esses dois mundos. Pôde-se, ainda, inferir que a flexibilização do mundo do trabalho engendra a flexibilização do mundo da vida. Desse modo, produz-se a noção de que seja possível trabalhar, ser pai/mãe, se divertir, descansar, produzir, tudo ao mesmo tempo e no mesmo lugar. Porém a impressão é de que sempre se está atrasado ou deslocado, fora do tempo ou do espaço, seja no ambiente doméstico ou do trabalho: é preciso adaptar-se. Cada sujeito deve utilizar-se de estratégias para poder responder a todas essas demandas. Ele deve gerir e administrar a própria carreira e vida pessoal de forma a cumprir com todas as exigências, nem que delegue a terceiros os 
cuidados com os filhos e familiares. Por outro lado, ficam perceptíveis os sofrimentos, as angústias, as incertezas, o espanto e, também, a conformidade com relação às constantes mudanças no mundo contemporâneo e com seus efeitos.

A análise desenvolvida neste artigo evidenciou, portanto, como as matérias da revista Você S.A. se revelaram um recurso profícuo para um maior entendimento de como a compressão espaciotemporal se efetiva na contemporaneidade. Especialmente, na medida em que foi possível aprofundar as reflexões sobre os modos de trabalhar e de viver na atualidade, visibilizados por uma abrangente mídia de negócios.

Cabe observar que a análise realizada no presente artigo não esgota a discussão sobre a compressão espaciotemporal, seja pela complexidade do tema seja pelos limites inerentes à pesquisa. A partir dos resultados aqui alcançados, sugere-se a importância de se desenvolver novos estudos do assunto. Um possível encaminhamento seria ampliar as fontes dos dados de pesquisa para outras mídias, ou ainda realizar entrevistas semi-estruturadas com o público-alvo dessas mídias e, adicionalmente, com funcionários de empresas. Desse modo, seria possível ampliar o entendimento dos modos de trabalhar e de viver na contemporaneidade, o que contribuiria significativamente para aprofundar a análise do engendramento ligado à compressão do tempo-espaço.

Artigo recebido em 03.09.2007. Aprovado em 24.06.2008.

\section{REFERENNCIAS BIBLIOGRÁFICAS}

Amabile, T. M., Mueller, J. S., Simpson, W. B., Hadley, C. N., Kramer, S. J., \& Fleming, L. (2002). Time pressure and creativity in organizations: a longitudinal field study [Working Paper $\mathrm{N}^{\circ} 02-$ 073]. Harvard Business School, Boston, MA, EUA.

Amanda, C. (2006, fevereiro). Ondas digitais. Revista Você S.A., 92, p. 94.

Ancona, D. G., Goodman, P. S., Lawrence, B. S., \& Tushman, M. L. (2001). Time: a new research lens. Academy Management Review, 26(4), 644-663.

Anônimo (2005, outubro). Ative sua energia positiva. Revista Você S.A., 88, pp. 88-89.

Anônimo (2006, fevereiro). As mazelas do mundo digital. Revista Você S.A., 92, p. 15.

Anônimo (2006, fevereiro). Ratinhos para todos. Revista Você S.A., 92, p. 95.

Anônimo (2006, junho). Incremente seu celular. Revista Você S.A., 96, p. 97.

Bardin, L. (1979). Análise de conteúdo (L. A. Reto \& A. Pinheiro, Trad.). São Paulo: Edições 70, Livraria Martins Fontes. (Obra original publicada em 1977).

Bauman, Z. (1999). Globalização: as conseqüências humanas (M. Penchel, Trad.). Rio de Janeiro: Jorge Zahar. (Obra original publicada em 1998).

Bauman, Z. (2001). Modernidade líquida (P. Dentzien, Trad.). Rio de Janeiro: Jorge Zahar. (Obra original publicada em 2000).

Bottoni, C. (2006, fevereiro). Felizes para sempre. Revista Você S.A., 94, pp. 48-50.

Costa, J. E. (2005, agosto). Entre a praia e a carreira. Revista Você S.A., 86, pp. 78-81.

Dias, A. (2005, setembro). Mães executivas. Revista Você S.A., 87, pp. 62-65. 
Foucault, M. (1995). O sujeito e o poder. In H. Dreyfus \& P. Rabinow. Michel Foucault, uma trajetória filosófica: para além do estruturalismo e da hermenêutica (P. Carrero, Trad.). Rio de Janeiro: Forense Universitária. (Obra original publicada em 1982).

Harvey, D. (2004). Condição pós-moderna (A. U. Sobral \& M. Stela, Trad.). São Paulo: Edições Loyola. (Obra original publicada em 1990).

Herzog, A. L., Dias, A., \& Costa, J. E. (2005, agosto). Salário: 1 executivo = 11 operários. Revista Você S.A., 86, p. 13.

Jacomino, D. (2005, agosto). Intoxicação high-tech. Revista Você S.A., 86, pp. 50-51.

Lazzarato, M., \& Negri, A. (2001). Trabalho imaterial: formas de vida e produção de subjetividade (M. Jesus, Trad.). Rio de Janeiro: DP\&A. (Obra original publicada em 1997).

Mari, J. (2005, agosto). Fora de controle. Revista Você S.A., 86, pp. 58-59.

Mari, J. (2005, novembro). Há vida lá fora. Revista Você S.A., 89, pp. 36-39.

Nogueira, J. (2006, fevereiro). Toda mesa é sua. Revista Você S.A., 92, pp. 64-69.

Oliveira, M. (2005, novembro). Pais sem happy-hour, filhos sem recreio. Revista Você S.A., 89, pp. 70-74.

Pagès, M., Bonetti, M., Gaulejac, V., \& Descendre, D. (1987). O poder das organizações (M. C. R. Tavares \& S. S. Favatti, Trad.). São Paulo. Atlas. (Obra original publicada em 1979).

Pelbart, P. P. (2000). A vertigem por um fio: políticas da subjetividade contemporânea. São Paulo: Iluminuras.

Pelbart, P. P. (2003). Vida capital. São Paulo: Iluminuras.

Perlow, L. A. (1999). The time famine: toward a sociology of work time. Administrative Science Quarterly, 44(1), 57-81.

Rego, R. (2005, agosto). Quando dizer não ao chefe. Revista Você S.A., 86, pp. 89-91.

Rodrigues, A. L., \& Morin, E. M. (2004, setembro). Mídia e reconhecimento profissional: a análise de conteúdo como recurso para exploração de práticas discursivas e impactos na qualidade de vida no trabalho de executivos. Anais do Encontro Nacional da Associação Nacional de PósGraduação e Pesquisa em Administração, Curitiba, PR, Brasil, 28.

Schibuola, T. (2005, novembro). Quer trabalhar meio período? Revista Você S.A., 89, pp. 40-41.

Schneider, A. (2006, fevereiro). Isto já é realidade. Revista Você S.A., 92, pp. 70-71.

Sennett, R. (1998). O declínio do homem público: as tiranias da intimidade (L. A. Watanabi, Trad.). São Paulo: Companhia das Letras. (Obra original publicada em 1976).

Virilio, P. (1999) A bomba informática (L. V. Machado, Trad.). São Paulo: Estação Liberdade. (Obra original publicada em 1998). 